\title{
Acute kidney injury in children after cardiac surgery: Risk factors and outcomes. A retrospective cohort study
}

\author{
M. Paula Graziani, M.D. ${ }^{a}$, Manuela Moser, M.D. ${ }^{a}$, C. Martín Bozzola, M.D. ${ }^{a}$, \\ Hugo M. Galvez, M.D. ${ }^{b}$, Julieta Irman Garrido, M.D. ${ }^{c}$, P. Guido Álvarez, M.D. ${ }^{d}$ and \\ M. Lucila Fernie, M.D. ${ }^{a}$ \\ Collaborators: Javier Mariani, M.D. and Glenda Ernst, M.D. Hospital Británico de \\ Buenos Aires, Scientific Advisory Committee.
}

\begin{abstract}
Introduction. Acute kidney injury (AKI) has been described as a common complication of cardiac surgery in pediatric patients, whose impact on morbidity and mortality has been documented. Its incidence has been estimated to be approximately $40 \%$ in this patient group. The objective of this study was toestimate theincidence of AKI in patients who underwent cardiovascular surgery and to define associated risk factors and the impact of AKI on the parameters of the postoperative course.

Population and methods. This was a retrospective, observational study of pediatric patients who underwent cardiovascular surgery between January 2015 and December 2017 at Hospital Británico de Buenos Aires. The incidence of AKI was defined as per the Kidney Disease: Improving Global Outcomes criteria, based on pre- and post-operative blood creatinine levels and urine output.

Results. A total of 125 patients were included. Of them, $35 \%$ developed AKI. The analysis of risk factors showed a statistically significant difference for the administration of vancomycin and thiazide diuretics, red blood cell transfusion requirement, extracorporeal circulation pump time, clamp time, maximal intraoperative lactate level, minimum temperature, and delayed chestclosure. In relation to the parameters of the post-operative course, we observed a longer hospital stay, higher inotropic requirement, more days of mechanical ventilation, bleeding, and neurological complications.

Conclusion. In this study, the incidence of AKI was $35 \%$. Modifiable and non-modifiable associated risk factors were defined and a greater rate of complications was observed in patients who developed AKI.

Key words: acute kidney injury, cardiovascular surgery, pediatrics.
\end{abstract}

http: / / dx.doi.org/10.5546/ aap.2019.eng.e557

To cite: Graziani MP, Moser M, Bozzola CM, Gálvez $\mathrm{HM}$, et al. Acute kidney injury in children after cardiac surgery: Risk factors and outcomes. A retrospective, cohort study. Arch Argent Pediatr 2019;117(6):e557-e567.

\section{INTRODUCTION}

Acute kidney injury (AKI) has been described as a common complication of cardiac surgery in pediatric patients, whose impact on morbidity and mortality has been documented. Its incidence has been described to be approximately $40 \%$ in this patient group. ${ }^{1}$

AKI has been associated with more days of mechanical ventilation, a higher inotropic requirement, a longer length of stay, and mortality, even in patients with small variations in creatinine levels. ${ }^{2-4}$

Delayed growth, hypertension, and chronic kidney failure have been described in the long term. ${ }^{5,6}$

The risk factors include high preoperative blood creatinine levels, age younger than 1 year, prolonged extracorporeal circulation time, higher inotrope requirements, and low postoperative cardiac output. ${ }^{1,3,7}$

Likewise, an association has been described with the greater surgery complexity, ${ }^{8}$ which is reflected on the risk adjustment for congenital heart surgery (RACHS-1) category. ${ }^{9,10}$

There are different definitions of AKI, which have gradually evolved seeking for a more accurate assessment. For example, the Risk, Injury, Failure, Loss, and End-stage (RIFLE) criteria, their pediatric adaptation (pRIFLE), and the Acute Kidney Injury Network (AKIN) classification. More recently, in 2012, the Kidney Disease: Improving Global Outcomes (KDIGO) group developed new criteria in an attempt to reconcile the differences among the previous 
definitions, ${ }^{2,11,12}$ and they have been validated in both children and adults. ${ }^{13-15}$

The pathophysiology of AKI in these patients involves multiple mechanisms: a low cardiac output, the release of pro inflammatory cytokines, the ischemia-reperfusion phenomenon, blood mechanical trauma, oxidative stress, and nephrotoxins. ${ }^{5,15}$

Identifying the risk factors would allow to develop strategies aimed at reducing morbidity and mortality. Therefore, the objective of this study was to estimate the incidence of AKI in patients who underwent cardiovascular surgery and to determine the associated risk factors and the impact of AKI on the parameters of the postoperative course.

\section{POPULATION AND METHODS Design}

This was a retrospective, observational cohort study of pediatric patients who underwent cardiovascular surgery between January 2015 and December 2017 at Hospital Británico de Buenos Aires, a referral tertiary care facility. Medical records were reviewed to collect the data of the study variables to be analyzed.

\section{Eligibility criteria}

Inclusion criteria

$\infty)$ Age younger than 16 years.

80 Surgery performed by the hospital's Cardiac Surgery Team between January 2015 and December 2017.

\section{Exclusion criteria}

80 Patients with incomplete or missing medical records.

\section{Recorded study variables}

$\infty_{0}$ Incidence of AKI: As per the KDIGO criteria (see Annex).

\&o Risk factors: Age, sex, weight, gestational age, birth weight, family history, comorbidities, type of heart disease, prior surgery, nephrotoxic drugs, inotropic use, RACHS-1 category, hypotension, transfusions, intravenous fluids, hyperglycemia, infections, arrhythmia, post-operative catheterization, extracorporeal circulation pump time, clamp time, delayed chest closure, maximal lactate level, minimum temperature, graft or prosthetic material use.

so AKI assessment: Creatinine levels, urea levels, and urine output (pre-operative, post- operative, at the time of AKI diagnosis, and worst level achieved).

80 Parameters of post-operative course: Length of stay in days, days of mechanical ventilation (MV), inotropes, renal function replacement therapy, cardiorespiratory arrest, extracorporeal membrane oxygenation (ECMO) requirement, multiple organ failure, and death. In addition, a combined event was defined, which included the occurrence of death and neurological, liver, infectious or bleeding post-operative complications.

\section{Ethical aspects}

This study was approved by the hospital's Institutional Review Board in accordance with the Declaration of Helsinki. Due to the study's retrospective nature, we requested the waiver of informed consent.

\section{Statistical analysis}

Continuous variables were described as mean and standard deviation (SD) for those with a normal distribution or as median and interquartile range (IQR) for those with an abnormal distribution. Categorical data were expressed as frequency and percentage. The assumption of normality was assessed using the Shapiro-Wilk test. Continuous data were assessed using the $t$ test in the case of normal distribution or the Mann-Whitney U test in case of abnormal distribution. Categorical data were compared with the $\chi^{2}$ test or Fisher's exact test, as applicable.

The association between potential risk factors and the occurrence of AKI was assessed using a multivariate logistic regression model, which included all variables with a $p$ value $<0.1$ in the univariate analysis (besides age, sex, and weight). The final model was selected by making all possible combinations of predictor variables included in the initial model and leaving those that showed a statistically significant association and the best predictive power (as per the Akaike information criterion). If predictor variables were continuous, receiver operating characteristic (ROC) curves were developed and the best cutoff point was identified using the Youden index. Regression analyses were then repeated using the dichotomized variables. For each predictor variable, the odds ratio (OR) and its corresponding $95 \%$ confidence interval $(\mathrm{CI})$ were calculated.

To assess the association between AKI and post-operative outcomes, multivariate regression models were used (a logistic regression for the 
combined event and a Poisson regression for the length of stay in days), and the development of AKI was used as a predictor variable, with adjustments for other confounding factors. The variables for these models were selected in the same way as described above for the occurrence of AKI, except that AKI was forced into the model in both cases. The multivariate association between length of stay in days and AKI in the Poisson regression analysis was described as an incidence rate ratio (IRR) and its corresponding $95 \%$ CI.

All analyses were two-tailed, and a $p$ value $<0.05$ was considered statistically significant. The sample size was determined by convenience because, due to logistical reasons, it was possible to include patients between the dates mentioned above. Analyses were done using the GraphPad Prism 8.0.1® and the R 3.5.1 software programs.

\section{RESULTS}

\section{Characteristics of the population under study}

During the study period, 145 patients underwent surgery; of them, 20 met the exclusion criteria, so a total of 125 patients were eligible and included in the study group. The incidence of post-operative AKI was $35 \%(\mathrm{n}=44)$. In this group, defined as "AKI patients," $70.5 \%(\mathrm{n}=31)$, $22.7 \%(\mathrm{n}=10)$, and $6.8 \%(\mathrm{n}=3)$ met the criteria for categories 1, 2, and 3 of AKI, respectively. Table 1 shows the characteristics of the population under study.

No statistically significant differences were observed in relation to the type of heart disease, except in the case of anomalous origin of left coronary artery from pulmonary artery (ALCAPA), which was more frequent in AKI patients (Table 2).

\section{Risk factors for acute kidney injury}

Table 3 shows the distribution of risk factors for AKI. Variables associated with the development of AKI in the univariate analysis were the administration of vancomycin $(p=0.012)$ and the use of thiazides $(p=0.015)$. However, no association was observed between AKI and infections, thrombosis, arrhythmia, greater surgical complexity as per the RACHS- 1 or postoperative catheterization as risk factors.

AKI patients showed a non-significant tendency towards a higher frequency of hyperglycemia. When the hypoperfusion and tissue hypoxia variables were analyzed as potential event triggers, AKI patients were observed to have a significantly higher requirement for red blood cell transfusions ( $p$ $<0.001)$. However, no significant differences were observed for pre-operative inotropic requirement as per the vasoactive inotropic score (VIS), ${ }^{16,17}$ the hypotension score (cardiovascular section of the Pediatric Sequential Organ Failure Assessment [pSOFA] $)^{1,18}$ or the fluid intake in the first $48 \mathrm{~h}$, as an indirect measure of low cardiac output.

A statistically significant difference was noted in terms of the intraoperative risk factors, such as extracorporeal circulation pump time $(p=0.008)$, clamp time $(p=0.016)$, delayed chest closure

TABLE 1. Characteristics of the study population

\begin{tabular}{|c|c|c|c|c|}
\hline Variable & $\begin{array}{c}\text { All } \\
(n=125)\end{array}$ & $\begin{array}{l}\text { Without AKI } \\
\quad(n=81)\end{array}$ & $\begin{array}{l}\text { With AKI } \\
(\mathrm{n}=44)\end{array}$ & $p$ value \\
\hline Male sex, n (\%) & $73(58.4)$ & $50(61.7)$ & $23(52.3)$ & 0.404 \\
\hline Age (months old), median (IQR) & $5.0(2.0-23.0)$ & $5.0(2.0-19.0)$ & $4.5(0.8-28.3)$ & 0.714 \\
\hline Preterm birth, n (\%) & $15(12.0)$ & $7(8.6)$ & $8(18.2)$ & 0.201 \\
\hline Low birth weight, $\mathrm{n}(\%)$ & $11(8.8)$ & $6(7.4)$ & $5(11.4)$ & 0.338 \\
\hline \multicolumn{5}{|l|}{ Comorbidity, n (\%) } \\
\hline Nephropathy & $7(5.6)$ & $5(6.2)$ & $2(4.5)$ & 1.00 \\
\hline Lung disease & $1(0.8)$ & $0(0)$ & $1(2.3)$ & 0.352 \\
\hline Genetic disorder & $20(16)$ & $11(13.6)$ & $9(20.5)$ & 0.456 \\
\hline \multicolumn{5}{|l|}{ Family history, n (\%) } \\
\hline Heart disease & $3(2.4)$ & $1(1.2)$ & $2(4.5)$ & 0.283 \\
\hline Nephropathy & $1(0.8)$ & $1(1.2)$ & $0(0.0)$ & 1.00 \\
\hline Prior surgery, n (\%) & $42(33.9)$ & $24(29.6)$ & $17(39.5)$ & 0.409 \\
\hline
\end{tabular}

AKI: acute kidney injury; IQR: interquartile range. 
$(p=0.016)$, maximal lactate level $(p=0.002)$, and minimum temperature $(p=0.041)$ (Figure 1 ).

The multivariate logistic regression analyses identified red blood cell transfusion and maximal lactate level as independent variables. For the first one, a cut-off value of $35 \mathrm{~mL} / \mathrm{kg}$ or higher was identified (OR: 3.26; $95 \%$ CI: 1.31-8.21; $p=0.011$ ), whereas for the second, the cut-off point was set at $26.5 \mathrm{mg} / \mathrm{dL}$ or higher (OR: 3.11; $95 \%$ CI: 1.28$7.61 ; p=0.012$ ).

\section{Parameters of post-operative course}

Table 3 shows the analysis of these parameters. A statistically significant increase in the length of stay in days and in the days of MV was observed in AKI patients $(p=0.005$ and $p<0.001$, respectively) (Figure 2. $A-B$ ). Likewise, a longer duration of inotropic use $(p<0.001)$ and a higher inotropic use as per the VIS $(p=0.010)$ were observed (Figure 2. C-D).

The development of AKI was associated with a higher risk for bleeding $(p=0.005)$ and neurological complications $(p=0.004)$. In total, $11.4 \%(\mathrm{n}=5)$ of AKI patients died, compared to $3.7 \%(n=3)$ of those who did not develop AKI $(p=0.131)$. All patients with multiple organ failure $(n=3)$ had AKI, which accounted for $6.8 \%$ of them. The only patient who was on ECMO had developed stage 3 kidney injury with peritoneal dialysis requirement. Out of all AKI patients, $9.1 \%$ required peritoneal dialysis. The combined event occurred in 12 patients $(14.8 \%)$ without AKI and in $18(40.9 \%)$ with AKI $(p=0.002)$.

The association between the length of stay in days and the development of AKI was no longer statistically significant after the adjustment for confounding factors (IRR: 1.05; $95 \%$ CI: 0.91$1,20 ; p=0.505)$. Something similar was observed with the combined event: the association between it and AKI was no longer significant after the adjustment for confounding variables (OR: 1.88; $95 \%$ CI: 0.46-7.62; $p=0.370$ ).

\section{Parameters for the measurement of acute kidney injury}

The patients who developed AKI had, in the immediate post-operative period, a higher blood creatinine level $(0.42 \pm 0.2$ versus $0.36 \pm 0.1 \mathrm{mg} /$ $\mathrm{dL} ; p=0.020)$ and a lower urine output $(1.6 \pm 1.3$ $\mathrm{mL} / \mathrm{kg} / \mathrm{h}$ versus $2.5 \pm 1.4 \mathrm{~mL} / \mathrm{kg} / \mathrm{h} ; p<0.001)$ (Figure 3. A-B). In relation to the time of AKI onset, $57 \%$ of patients developed it in the first day after the surgery; $29 \%$, on the second day; and the rest, in the subsequent days; the latest case occurred 27 days after the surgery. In relation to the duration in hours, most cases resolved within $24 \mathrm{~h}(65 \%)$ (Figure 3. C-D).

The association between the AKI stage and the RACHS-1 categories was not observed to be statistically significant, but there was a relevant proportional increase in the AKI stage based on the RACHS-1 category.

TABLE 2. Incidence of acute kidney injury by type of underlying heart disease

\begin{tabular}{|c|c|c|c|}
\hline Heart disease & Without AKI (n = 81) & With AKI $(n=44)$ & $p$ value \\
\hline Tetralogy of Fallot, n (\%) & $13(16.0)$ & $5(11.4)$ & 0.656 \\
\hline Single ventricle, n (\%) & $12(14.8)$ & $3(6.8)$ & 0.305 \\
\hline Ventricular septal defect, n (\%) & $9(11.1)$ & $6(13.6)$ & 0.899 \\
\hline Coarctation of the aorta, $\mathrm{n}(\%)$ & $10(12.3)$ & $2(4.5)$ & 0.212 \\
\hline Atrioventricular canal, $\mathrm{n}(\%)$ & $8(9.9)$ & $2(4.5)$ & 0.492 \\
\hline Pulmonary atresia/stenosis, n (\%) & $6(7.4)$ & $3(6.8)$ & 1.00 \\
\hline Shone's complex, n (\%) & $5(6.2)$ & $4(9.1)$ & 0.719 \\
\hline Transposition of the great arteries, $\mathrm{n}(\%)$ & $5(6.2)$ & $3(6.8)$ & 1.00 \\
\hline Atrial septal defect, n (\%) & $5(6.2)$ & $1(2.3)$ & 0.424 \\
\hline Hypoplasia of the left chambers, $n(\%)$ & $1(1.2)$ & $4(9.1)$ & 0.051 \\
\hline ALCAPA, n (\%) & $0(0.0)$ & $3(6.8)$ & 0.042 \\
\hline Anomalous venous return, $\mathrm{n}(\%)$ & $2(2.5)$ & $1(2.3)$ & 1.00 \\
\hline Interruption of the aortic arch, $\mathrm{n}(\%)$ & $1(1.2)$ & $2(4.5)$ & 0.283 \\
\hline Patent ductusarteriosus, $\mathrm{n}(\%)$ & $1(1.2)$ & $1(2.3)$ & 1.00 \\
\hline Truncusarteriosus, $\mathrm{n}(\%)$ & $0(0.0)$ & $2(4.5)$ & 0.122 \\
\hline Aortic stenosis, $\mathrm{n}(\%)$ & $0(0.0)$ & $1(2.3)$ & 0.352 \\
\hline Double-outlet right ventricle, n (\%) & $1(1.2)$ & $0(0.0)$ & 1.00 \\
\hline Aortopulmonary window, $\mathrm{n}(\%)$ & $1(1.2)$ & $0(0.0)$ & 1.00 \\
\hline Other, $\mathrm{n}(\%)$ & $1(1.2)$ & $1(2.3)$ & 1.00 \\
\hline
\end{tabular}

ALCAPA: anomalous origin of left coronary artery from pulmonary artery. 


\section{DISCUSSION}

AKI is one of the most common complications in pediatric patients who undergo surgery for congenital heart disease. The incidence of
AKI in our patients, as per the KDIGO criteria, was $35 \%$, which is slightly below what has been described in the bibliography. ${ }^{1,3-5,19}$ Such difference is attributed to the fact that most of

TABLE 3. Pre-, intra-, and post-operative variables analyzed as potential risk factors and parameters of post-operative course

\begin{tabular}{|c|c|c|c|}
\hline Variable & Nithout AKI ( $n=81)$ & With AKI $(\mathrm{n}=44)$ & $p$ value \\
\hline \multicolumn{4}{|l|}{ RISK FACTORS } \\
\hline Duration of pre-operative MV (days), mean \pm SD & $\begin{array}{c}0.4 \pm 2.01 \\
{[0-14]}\end{array}$ & $\begin{array}{c}1.2 \pm 3.9 \\
{[0-23]}\end{array}$ & 0.160 \\
\hline \multicolumn{4}{|l|}{ Pre-operative inotropes, mean \pm SD } \\
\hline Duration (days) & $\begin{array}{l}0.4 \pm 2 \\
{[0-14]}\end{array}$ & $\begin{array}{c}0.7 \pm 2.3 \\
{[0-12]}\end{array}$ & 0.319 \\
\hline Higher VIS & $\begin{array}{c}0.5 \pm 2.2 \\
{[0-16]}\end{array}$ & $\begin{array}{l}1 \pm 2.9 \\
{[0-13]}\end{array}$ & 0.185 \\
\hline \multicolumn{4}{|l|}{ Drugs, n (\%) } \\
\hline NSAIDs & $76(93.8)$ & $39(88.6)$ & 0.516 \\
\hline Vancomycin & $7(8.6)$ & $12(27.3)$ & 0.012 \\
\hline Penicillins & $6(7.4)$ & $7(15.9)$ & 0.218 \\
\hline Cephalosporins & $2(2.5)$ & $2(4.5)$ & 0.613 \\
\hline TMS & $0(0.0)$ & $1(2.3)$ & 0.352 \\
\hline Aminoglycosides & $1(1.2)$ & $3(6.8)$ & 0.125 \\
\hline Diuretics (in general) & $77(95.1)$ & $44(100)$ & 0.296 \\
\hline Loop diuretics & $77(95.1)$ & $44(100)$ & 0.296 \\
\hline Thiazide diuretics & $14(17.3)$ & $17(38.6)$ & 0.015 \\
\hline Potassium-sparing diuretics & $48(59.3)$ & $26(59.1)$ & 1.00 \\
\hline ACE inhibitors & $23(28.4)$ & $14(31.8)$ & 0.845 \\
\hline Prostaglandins & $11(13.6)$ & $8(18.2)$ & 0.672 \\
\hline RACHS-1, mean \pm SD & $\begin{array}{c}2.5 \pm 1.2 \\
{[1-6]}\end{array}$ & $\begin{array}{c}2.8 \pm 1.2 \\
{[1-6]}\end{array}$ & 0.199 \\
\hline Hypotension on day 1 after surgery, mean \pm SD & $\begin{array}{c}2.5 \pm 1 \\
{[0-4]}\end{array}$ & $\begin{array}{c}2.8 \pm 0.8 \\
{[0-4]}\end{array}$ & 0.264 \\
\hline Total fluid intake in the first $48 \mathrm{~h}(\mathrm{~mL} / \mathrm{kg} /$ day $)$, mean $\pm \mathrm{SD}$ & $\begin{array}{c}80.2 \pm 28 \\
{[19-195]}\end{array}$ & $\begin{array}{c}84.1 \pm 32.4 \\
{[25-203]}\end{array}$ & 0.556 \\
\hline Red blood cell transfusion requirement (mL/total kg) & $\begin{array}{c}22.4 \pm 16 \\
{[0-84]}\end{array}$ & $\begin{array}{c}50.5 \pm 49.4 \\
{[14-266]}\end{array}$ & $<0.001$ \\
\hline \multicolumn{4}{|l|}{ Hyperglycemia during fasting, n (\%) } \\
\hline$>140(\mathrm{mg} / \mathrm{dl})$ & $68(84.0)$ & $40(90.9)$ & 0.417 \\
\hline$>200(\mathrm{mg} / \mathrm{dl})$ & $53(65.4)$ & $34(77.3)$ & 0.242 \\
\hline Infections, $\mathrm{n}(\%)$ & $7(8.6)$ & $7(15.9)$ & 0.244 \\
\hline Arrhythmia, n (\%) & $6(7.4)$ & $7(15.9)$ & 0.218 \\
\hline Post-operative catheterization, $\mathrm{n}(\%)$ & $1(1.2)$ & $1(2.3)$ & 1.00 \\
\hline Extracorporeal circulation pump requirement, $\mathrm{n}(\%)$ & $70(86.4)$ & $42(95.5)$ & 0.137 \\
\hline Pump time (min), mean \pm SD & $\begin{array}{c}58.1 \pm 39.9 \\
{[0-160]}\end{array}$ & $\begin{array}{c}82.9 \pm 47.9 \\
{[0-218]}\end{array}$ & 0.008 \\
\hline Clamp time (min), mean \pm SD & $\begin{array}{c}34.7 \pm 30.5 \\
{[0-119]}\end{array}$ & $\begin{array}{c}51.1 \pm 36.2 \\
{[0-157]}\end{array}$ & 0.016 \\
\hline Delayed chest closure, n (\%) & $3(3.7)$ & $8(18.2)$ & 0.016 \\
\hline Maximal intraoperative lactate level $(\mathrm{mg} / \mathrm{dL})$, mean $\pm \mathrm{SD}$ & $\begin{array}{c}21.5 \pm 8.9 \\
{[7-55]}\end{array}$ & $\begin{array}{c}34.2 \pm 24.3 \\
{[9-124]}\end{array}$ & 0.002 \\
\hline Minimum intraoperative temperature $\left({ }^{\circ} \mathrm{C}\right)$, mean $\pm \mathrm{SD}^{*}$ & $\begin{array}{c}31.5 \pm 3.1 \\
{[21.6-37.2]}\end{array}$ & $\begin{array}{l}30.3 \pm 3.7 \\
{[20-36.3]}\end{array}$ & 0.041 \\
\hline Graft use, n $(\%)$ & $34(41.9)$ & $19(43.2)$ & 1.00 \\
\hline Prosthetic material use, n (\%) & $33(40.7)$ & $24(54.5)$ & 0.217 \\
\hline
\end{tabular}


Among the studied risk factors, no differences were observed in terms of the incidence of AKI as per the RACHS- 1 category, but there were differences between this and the AKI stage in the patients who developed it. It would appear then that, although surgery for congenital heart disease is a risk factor itself for the development of AKI and such complication may have a multifactorial origin, the greater surgical complexity would favor the development of higher AKI stages. Among the studied nephrotoxic drugs, an association was observed between AKI and the use of vancomycin and thiazide diuretics. For this reason, it may be concluded that, as well as in the general pediatric population, in these patients, strategies for the rational use of antibiotic, diuretics and other drugs should be recommended; because, even though these are complex patients with prolonged hospitalizations and risk for infection, it is important to consider the greater impact that drug nephrotoxicity has on them. Consistent with prior publications, a greater incidence of AKI in patients who had higher hyperglycemia levels has been demonstrated; ${ }^{21,22}$ however, such association was not statistically significant and, based on the studies reviewed to date, no recommendations have been found in relation to a strict hyperglycemia control.,22

Considering that a pathophysiological hypothesis suggests that a low cardiac output
A

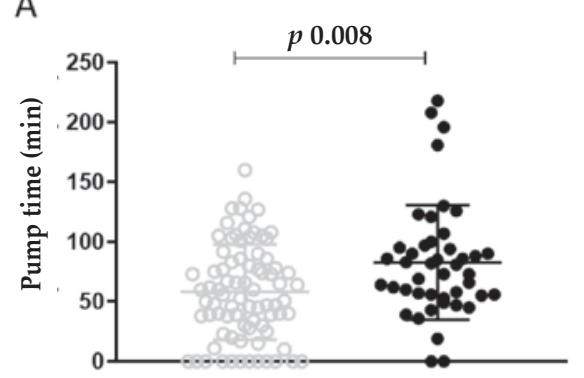

C

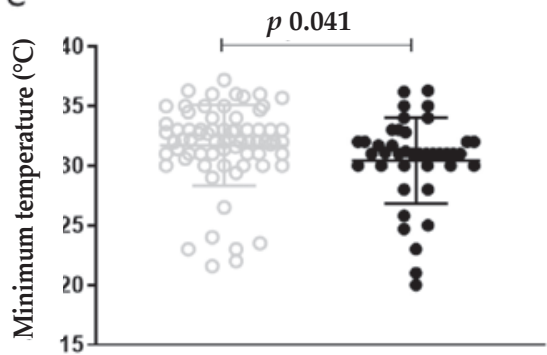

B

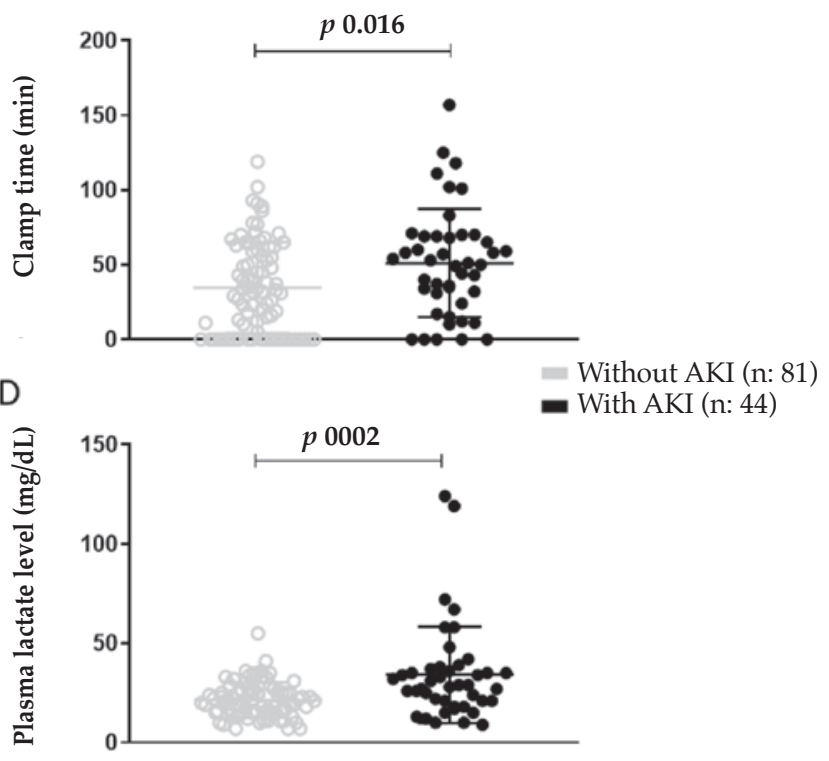

E Other intraoperative parameters

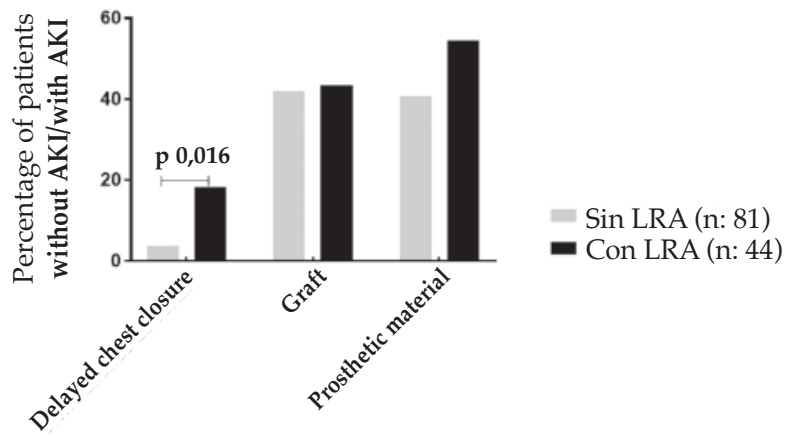

A) Pump time; B) Clamp time; C) Minimum temperature; D) Maximal lactate level; E) Other intraoperative parameters. AKI: acute kidney injury. 
and tissue hypoxia may trigger $\mathrm{AKI}{ }^{1,19}$ variables for the indirect measurement of these two factors have been analyzed. An association was observed between a greater red blood cell transfusion requirement and the incidence of AKI, but not between $\mathrm{AKI}$ and a higher inotropic requirement in the pre-operative period, hypotension score or a higher total fluid intake. On the basis of this, the impact of tissue hypoxia (as indirectly measured by transfusion requirement) would be greater than that of a low cardiac output. In addition, and considering the intra-operative variables, it has been observed that the incidence of AKI was higher with a longer pump time, clamp time and higher plasma lactate levels and with a lower temperature during surgery. These findings were similar to those reported in the bibliography. $1,3,14,19$

Finally, the analysis of the impact of AKI on morbidity and mortality showed that AKI patients had a greater rate of multiple organ failure and death. Likewise, in this group, a longer length of stay after the surgery, more days of MV, a higher inotropic requirement, and a greater incidence of bleeding, liver and neurological complications were detected.

\section{CONCLUSIONS}

The incidence of AKI in pediatric patients who underwent cardiovascular surgery was $35 \%$ in this study.

The analysis of the assessed risk factors showed a statistically significant difference for the administration of vancomycin and thiazide diuretics, red blood cell transfusion requirement, extracorporeal circulation time, clamp time, maximal intraoperative lactate level, minimum temperature, and delayed chest closure. In relation to the parameters of the post-
A

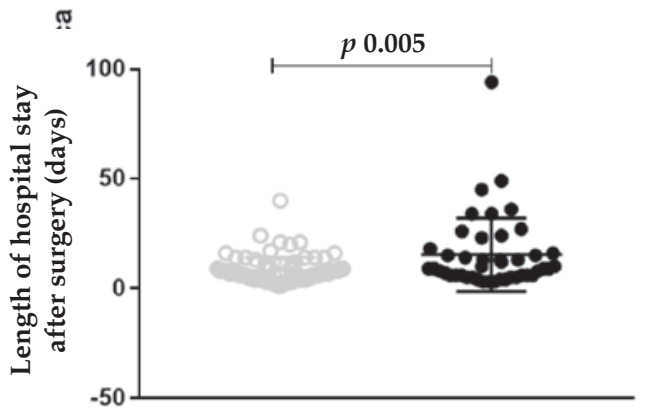

$\bar{\alpha}$

C

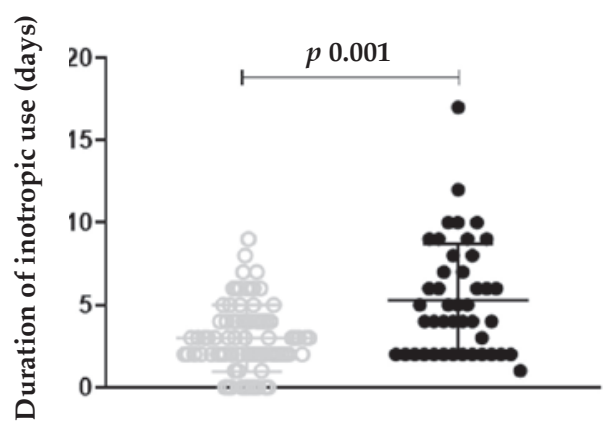

B

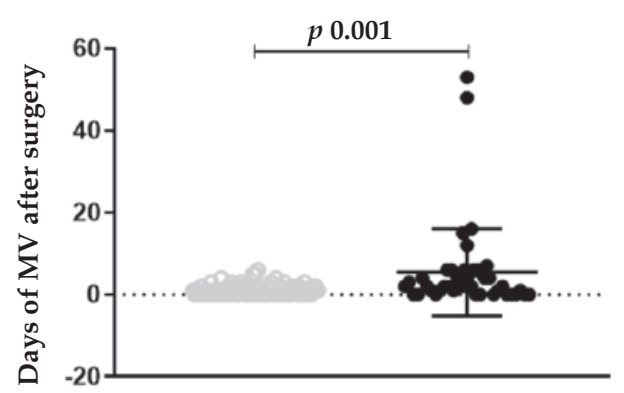

D

Without AKI (n: 81)

-With AKI (n: 44)

A) Length of stay in days; B) Days of MV; C) Duration of inotropic use; D) VIS.

MV: mechanical ventilation; VIS: vasoactive inotropic score.

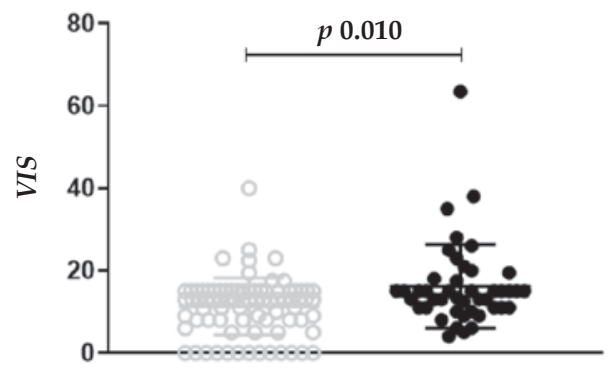


FIGURE 3. Assessment of kidney function

A

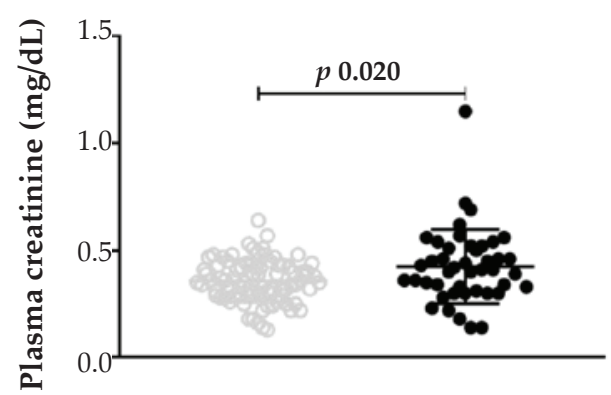

C
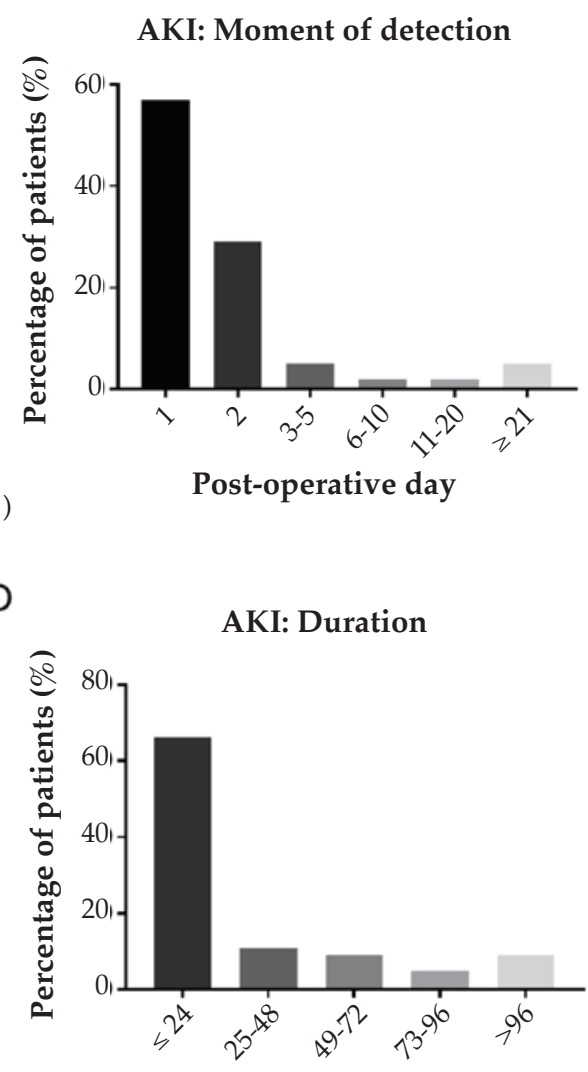

B

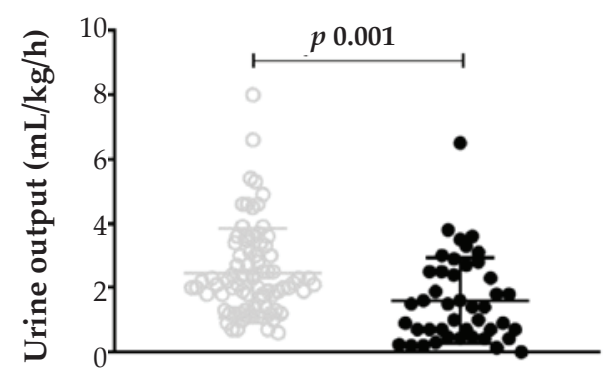

D

Without AKI (n: 81)

With AKI (n: 44)

Hours

A) Creatinine in the immediate post-operative period; B) Urine output in the immediate post-operative period;

C) Moment of AKI detection; D) Duration of AKI.

AKI: acute kidney injury.

operative course, we detected a statistically significant longer hospital stay, higher inotropic requirement, more days of mechanical ventilation, bleeding, and neurological complications.

\section{REFERENCES}

1. Li S, Krawczeski CD, Zappitelli M, Devarajan P, et al. Incidence, risk factors, and outcomes of acute kidney injury after pediatric cardiac surgery: a prospective multicenter study. Crit Care Med. 2011; 39(6):1493-9.

2. Kaddourah A, Basu RK, Bagshaw SM, Goldstein SL. Epidemiology of acute kidney injury in critically ill children and young adults. N Engl J Med. 2017; 376(1):11-20.

3. Aydin SI, Seiden HS, Blaufox AD, Parnell VA, et al. Acute Kidney Injury After Surgery for Congenital Heart Disease. Ann Thorac Surg. 2012; 94(5):1589-95.

4. Dos Santos El Halal MG, Carvalho PR. Acute kidney injury according to pediatric RIFLE criteria is associated with negative outcomes after heart surgery in children. Pediatr Nephrol. 2013; 28(8):1307-14.

5. Jefferies JL, Devarajan P. Early detection of Acute Kidney Injury after pediatric cardiac surgery. Prog Pediatr Cardiol. 2016; 41:9-16

6. Madsen NL, Goldstein SL, Frolsev T, Christiansen CF, et al. CardiacSurgery in patients with congenital heart disease is associated with acute kidney injury and the risk of chronic kidney disease. Kidney Int. 2017; 92(3):751-6.

7. Blinder JJ, Asaro LA, Wypij D, Selewski DT, et al. Acute Kidney Injury After Pediatric CardiacSurgery: A Secondary Analysis of the Safe Pediatric Euglycemia After Cardiac Surgery Trial. Pediatr Crit Care Med. 2017; 18(7):638-46.

8. Kumar TK, Allen CcpJ,Spentzas T, Berrios Ccp L, etal. Acute Kidney Injury Following Cardiac Surgery in Neonates and Young Infants: Experience of a Single Center Using Novel Perioperative Strategies. World J Pediatr Congenit Heart Surg. 2016; 7(4):460-6.

9. Ithuralde M, Ferrante D, Seara C, Ithuralde A, etal. Análisis dela mortalidad y distribución de procedimientos de cirugía de cardiopatías congénitas utilizando el método de ajuste de riesgo RACHS-1. Rev Argent Cardiol. 2007; 75(3):179-84.

10. Jacobs JP, Jacobs ML, Lacour-Gayet FG, Jenkins KJ, et al. Stratification of Complexity Improves the Utility and Accuracy of Outcomes Analysis in a Multi-Institutional Congenital Heart Surgery Database: Application of the Risk Adjustment in Congenital Heart Surgery (RACHS-1) and Aristotle Systems in the Society of Thoracic Surgeons (STS) Congenital Heart Surgery Database. Pediatr Cardiol. 2009; 30(8):1117-30.

11. Kellum JA, Lameire N, Aspelin P, Barsoum RS, et al. Kidney Disease: Improving Global Outcomes (KDIGO) Acute Kidney Injury Work Group. KDIGOClinical Practice 
Guideline for Acute Kidney Injury. Kidney Int Suppl. 2012; 2(1):1-138

12. Sutherland SM, Byrnes JJ, Kothari M, Longhurst CA, et al. AKI in Hospitalized Children: comparing the pRIFLE, AKIN, and KDIGO definitions. Clin J Am Soc Nephrol. 2015; 10(4):554-61.

13. SelewskiDT,Cornell TT,Heung M, TroostJP, etal.Validation of theKDIGOacutekidney injury criteriain a pediatric critical care population. Intensive Care Med. 2014; 40(10):1481-8.

14. Gist KM, Kwiatkowski DM, Cooper DS. Acute kidney injury in congenital heart disease. Curr Opin Cardiol. 2017; 32(1):101-7.

15. Toda $Y$, Sugimoto K. AKI after pediatric cardiac surgery for congenital heart diseases-recent developments in diagnostic criteria and early diagnosis by biomarkers. J Intensive Care. 2017; 5:49.

16. Gaies MG, Jeffries HE, Niebler RA, Pasquali SK, et al. Vasoactive-Inotropic Score is associated with outcome after infant cardiac surgery: an analysis from the Pediatric Cardiac Critical Care Consortium and Virtual PICU System Registries. Pediatr Crit Care Med. 2014; 15(6):529-37.

17. Davidson J, Tong S, Hancock H, Hauck A, et al. Prospective validation of the vasoactive-inotropic score and correlation to short term outcomes in neonates and infants after cardiothoracic surgery. Intensive Care Med. 2012; 38(7):1184-90.
18. Matics T, Sanchez-Pinto L. Adaptation and Validation of a Pediatric Sequential Organ Failure Assessment Score and Evaluation of the Sepsis-3 Definitions in Critically ill children. JAMA Pediatr. 2017; 171(10):e172352.

19. Park SK, Hur M, Kim E, Kim WH, et al. Risk Factors for Acute Kidney Injury after Congenital Cardiac Surgery in Infants and Children: A Retrospective ObservationalStudy. PLoS One. 2016; 11(11): $\mathrm{e} 0166328$.

20. Lex D, Tóth R, Cserép Z, Alexander SI, et al. A comparison of the systems for the identification of postoperative acute kidney injury in pediatric cardiac patients. Ann Thorac Surg. 2014; 97(1):202-10.

21. Preissig CM, Rigby MR, Maher KO. Glycemic control for postoperative pediatric cardiac patients. Pediatr Cardiol. 2009; 30(8):1098-104.

22. Agus MSD, Wypij D, Hirshberg EL, Srinivasan V, et al. Tight Glycemic Control in Critically Ill Children. N Engl J Med. 2017; 376(8):729-41.

23. Abman SH, Hansmann G, Archer SL, Ivy DD, et al. Pediatric Pulmonary Hypertension: Guidelines from the American Heart Association and American Thoracic Society. Circulation. 2015; 132(21):2037-99.

24. Soto-Martinez M, Massie J. Chylothorax: diagnosis and management in children. Pediatr Respir Rev. 2009; 10(4): 199-207. 


\section{ANNEX \\ Definition and staging of acute kidney injury as per the Kidney Disease: Improving Global Outcomes criteria}

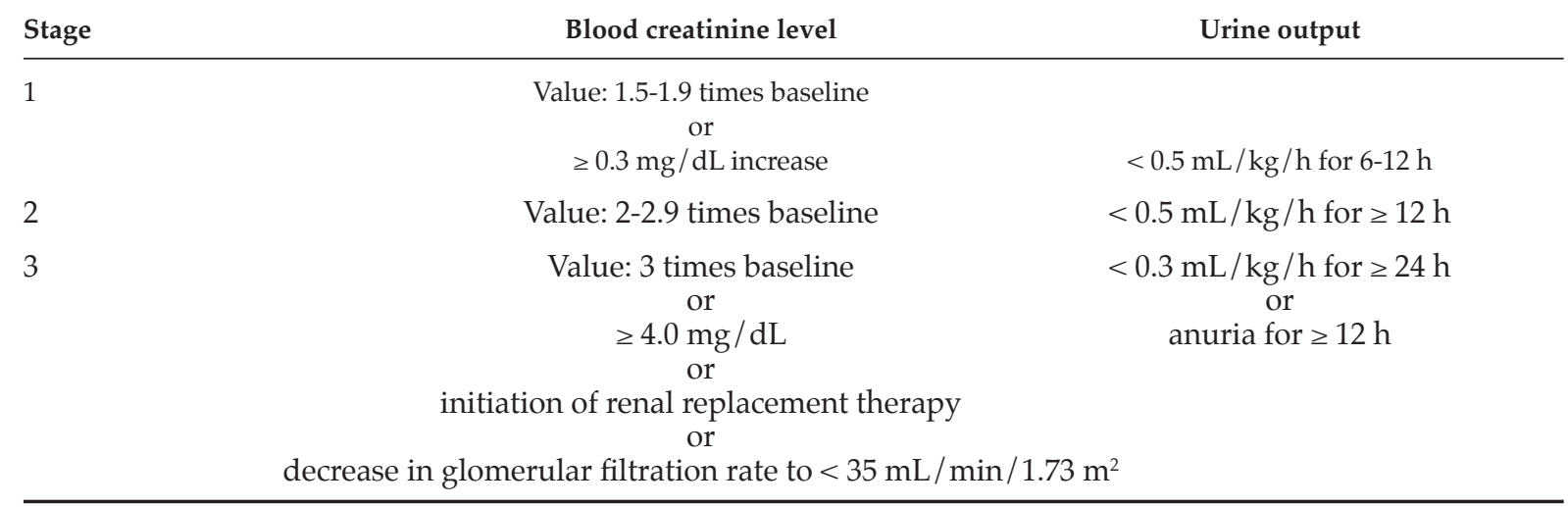

